\title{
Pharmacokinetics of Purified Paeonol and Paeonol in Moutan Cortex Decoction and Rhubarbmoutan Decoction
}

\author{
Wu Jing ${ }^{1 *}$, Zhang Rui ${ }^{2}$, Yuan Gui-yan ${ }^{2}$ and Guo Rui-chen ${ }^{2 *}$
}

${ }^{1}$ Pharmacy department, The Second Hospital of Shandong University, Jinan 250033, China

${ }^{2}$ Institute of Clinical Pharmacology, Qilu Hospital of Shandong University, Jinan 250012, China

\begin{abstract}
$180 \mathrm{KM}$ male mice of 22 28g body weight were divided into three groups randomly and purified paeonol, Moutan Cortex decoction and Rhubarbmoutan decoction were orally administered at equivalent doses of $10 \mathrm{mg} \cdot \mathrm{kg}^{-1}$ paeonol. A sensitive HPLC method was established and evaluated for determining the concentrations of paeonol in mice plasma. The main pharmacokinetic parameters of paeonol were as follows: $t_{1 / 2},(13.15 \pm 2.48) \mathrm{min},(15.04 \pm 4.40)$ min and (21.83 \pm 6.21$) \mathrm{min}, T_{\text {max }}, 15 \mathrm{~min}, 15 \mathrm{~min}$ and $10 \mathrm{~min}, C_{\text {max }}(69.41 \pm 4.50) \mathrm{ng} \cdot \mathrm{mL}^{-1},(82.90 \pm 6.10) \mathrm{ng} \cdot \mathrm{mL}^{-1}$ and $(123.32 \pm 5.55) \mathrm{ng} \cdot \mathrm{mL}^{-1}, A \cup C_{0-x^{\prime}}(1243.42 \pm 109.75) \mathrm{ng} \cdot \min \cdot \mathrm{mL}^{-1},(1412.74 \pm 97.72) \mathrm{ng} \cdot \mathrm{min} \cdot \mathrm{mL}^{-1}$ and $(2162.20 \pm 105.10)$ $\mathrm{ng} \cdot \mathrm{min} \cdot \mathrm{mL}^{-1}, A U C_{0 \infty},(2192.46 \pm 472.18) \mathrm{ng} \cdot \mathrm{min} \cdot \mathrm{mL}^{-1},(2659.57 \pm 1590.70) \mathrm{ng} \cdot \mathrm{min} \cdot \mathrm{mL}^{-1}$ and $(3423.36 \pm 465.40)$ $\mathrm{ng} \cdot \mathrm{min} \cdot \mathrm{mL}^{-1}$, respectively. All the results indicate that disposition in mice were affected by other components in Chinese herbs and in recipe.
\end{abstract}

Keywords: Paeonol; Moutan Cortex decoction; Rhuborbmoutan decoction; Pharmacokinetics; HPLC

\section{Introduction}

Paeonol is a major component extracted from Chinese herbs Moutan cortex [1], with the melting point of 51-52 [2]. Paeonol can relieve fever and promote blood flow, was widely used for its nonanalgesiadependence, better tolerance and less side effects. Rhubarbmoutan decoction [3], composed of $3 \mathrm{~g}$ Rhubarb and $12 \mathrm{~g}$ Moutan cortex as principal, $9 \mathrm{~g}$ Peach seed and $9 \mathrm{~g}$ Glauber salt as ministerial, and 30 g Chinese Waxgourd seed as adjunctive, can relieve stagnant and detumescence and was clinically used in acute appendicitis.

Several methods were reported for determining paeonol in herbs or in traditional prescriptions for quality control. HPLC method was developed for determining paeonol in rat [4,5,6], dog [7] or human [8,9] plasma and pharmacokinetics of paeonol were also studied respectively. Chinese traditional herbs or compound recipe are complex systems with multiple components [10], in which synergistic or antagonism effects might exist. In this study, a sensitive HPLC method was established for paeonol determination and pharmacokinetic differences of paeonol, in Moutan cortex decoction and Rhubarbmoutan decoction were studied and evaluated.

\section{Materials and Methods}

\section{Apparatus and reagents}

Waters 515-2487 HPLC, LXJ High Speed Centrifuge, PK514BP Superwave Cleaner, and AX 205 Meteller-Toledo Scale were supplied by Waters, Agillent Technologies, the Shanghai Analysis Instrument Factory, and Metteler-Toledo Instrument (Shanghai) Co.Ltd, respectively. Paeonol tablets, 40mg per tablet, and paeonol standard (99\%) were provided by Liu-Zhou (Guangxi) and Lu-Ye (Shandong) Co.Ltd, respectively.Methanol, acetonitrile and tetrahydrofuran, spectrum grade, were purchased from Tedia Company, USA. Phosphoric acid, analytical grade, and sodium chloride, from Tianjin Shen-Tai Chemicals and Weihai Ya-Tai Medcine Co.Ltd, respectively.

\section{Decoction preparation}

The paeonol, Moutan cortex decoction and Rhubarbmoutan decoction were prepared at the same concentration of $0.3 \mathrm{mg} \cdot \mathrm{mL}^{-1}$ (paeonol). Reflux condenser was used for preparation of Moutan cortex decoction and Rhubarbmoutan decoction. The preparing flowcharts of those two decoction were shown in Figure 1 and Figure 2. No significant change was detected in paeonol concentration within $12 \mathrm{~h}$ under the conditions.

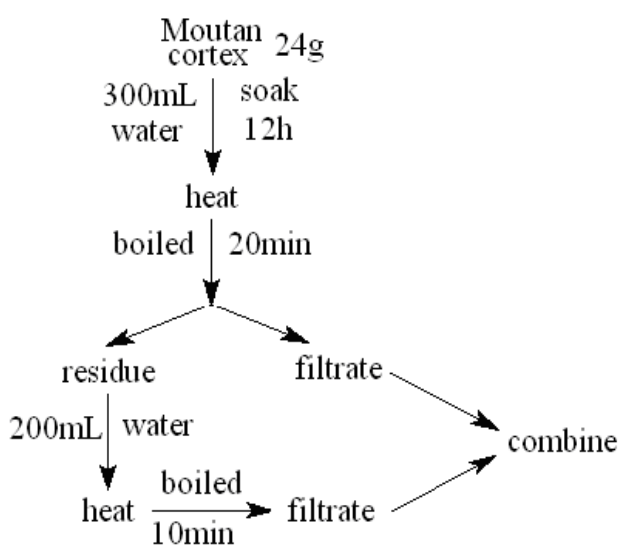

Figure 1: Flowchart of Moutan cortex decoction.

${ }^{*}$ Corresponding authors: WU Jing, female, postgraduate, pharmacist majoring in the clinical pharmacology, China, Tel: 15954907800; E-mail: wujing19830603@126.com

GUO Rui-chen, correspondence author, professor, tutor of doctor, majoring in clinical pharmacology and pharmacokinetics, China, Tel: 0531-82169636: E-mail: grc7636@126.com

Received June 07, 2011; Accepted June 22, 2011; Published June 24, 2011

Citation: Jing W, Rui Z, Gui-yan Y, Rui-chen G (2011) Pharmacokinetics of Purified Paeonol and Paeonol in Moutan Cortex Decoction and Rhubarbmoutan Decoction. Pharm Anal Acta 2:124. doi:10.4172/2153-2435.1000124

Copyright: (c) 2011 Jing W, et al. This is an open-access article distributed under the terms of the Creative Commons Attribution License, which permits unrestricted use, distribution, and reproduction in any medium, provided the original author and source are credited. 


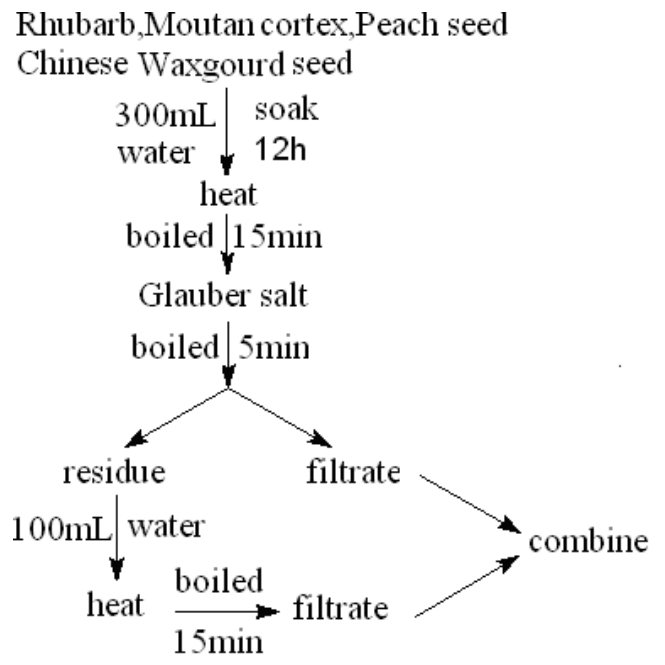

Figure 2: Flowchart of Rhuborbmoutan decoction.

\section{Study design}

$180 \mathrm{KM}$ male mice [11] of 22 28 g body weight were divided into three groups and purified paeonol, Moutan Cortex decoction and Rhuborbmoutan decoction equivalent to $10 \mathrm{mg} \cdot \mathrm{kg}^{-1}$ of paeonol were orally administered. $0.3 \mathrm{~mL}$ blood was collected by the blood samples were taken in the studied mice by penetrating the retro-orbital sinus with a glass capillary at $5,7,10,15,20,25,30,40,50$ and $60 \mathrm{~min}$. One time point was corresponding to 6 mice for average. The concentration of paeonol in plasma was determined with HPLC method. The main pharmacokinetic parameters of paeonol were calculated by DAS 2.0 and the influences of other components in Moutan Cortex and Rhuborbmoutan decoction were evaluated.

\section{Chromatographic conditions}

Paeonol was separated by Hypersil $\mathrm{C}_{18}$ column $(250 \mathrm{~mm} \times 4.6 \mathrm{~mm}$ i.d., $5 \mu \mathrm{m})$ at 25 [8]. Isocratic elution of the analyte from the column was achieved with the mobile phase consisting of $1 \mathrm{mmoL} \cdot \mathrm{L}^{-1}$ phosphoric acid (containing $1 \%$ triethylamine)-acetonitrile $(40: 60, \mathrm{v} / \mathrm{v})$ at a flow rate of $1.0 \mathrm{~mL} \cdot \mathrm{min}^{-1}$.

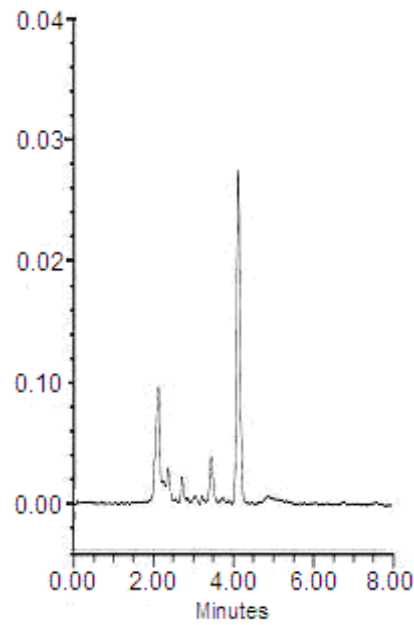

A

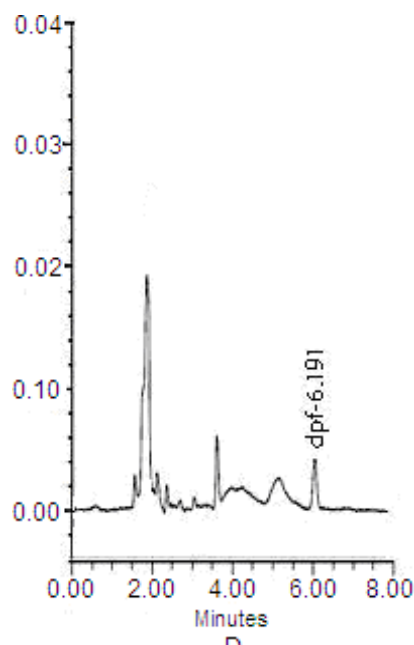

D

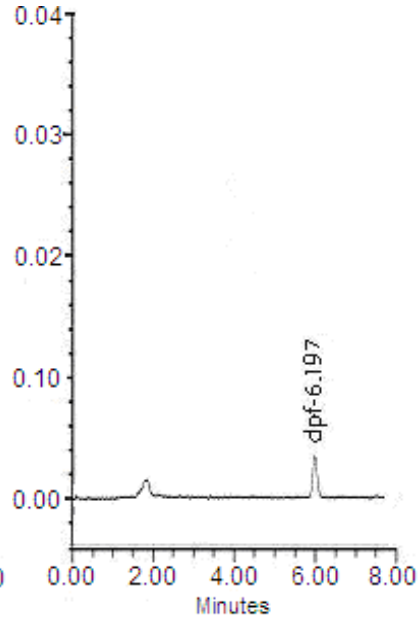

$\mathrm{B}$

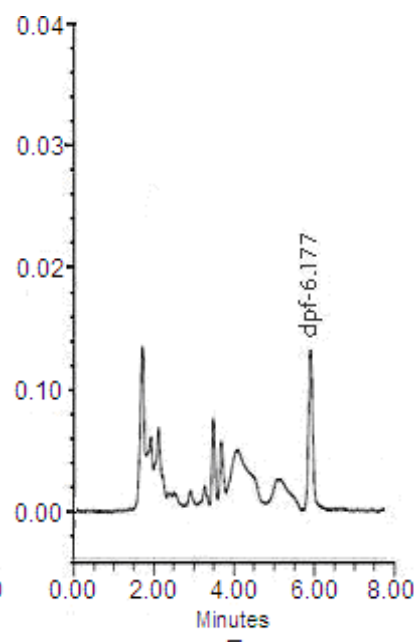

E
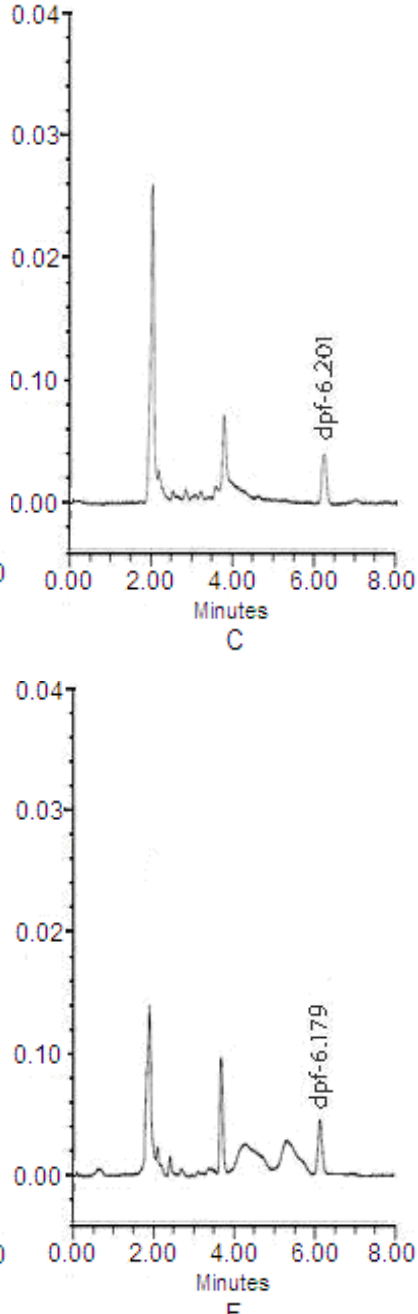

F

Figure 3: The chromatograms of blank plasma (A), $200 \mathrm{ng} \cdot \mathrm{mL}^{-1}$ paeonol standard (B), blank plasma spiked with $250 \mathrm{ng} \cdot \mathrm{mL}^{-1}$ paeonol standard (C) , plasma sample 5 min after intragastric administration of purified paeonol (D), Moutan cortex decoction(E) and Rhubarbmoutan decoction (F). 
Citation: Jing W, Rui Z, Gui-yan Y, Rui-chen G (2011) Pharmacokinetics of Purified Paeonol and Paeonol in Moutan Cortex Decoction and Rhubarbmoutan Decoction. Pharm Anal Acta 2:124. doi:10.4172/2153-2435.1000124

Page 3 of 4

\section{Sample disposition}

$0.2 \mathrm{~mL}$ plasma sample plus $0.2 \mathrm{~mL}$ acetonitrile were vortex-mixed for $30 \mathrm{~s}$, then centrifuged at $10080 \mathrm{rpm}$ (revolutions per minute) for $5 \mathrm{~min}$. The upper organic layer was transferred into tubes containing 40 50 mg sodium chloride, then vortex-mixed for $30 \mathrm{~s}$ and incubated at room temperature for $10 \mathrm{~min}$, centrifuged again at $10080 \mathrm{rpm}$ for $5 \mathrm{~min}$, and $5 \mathrm{~mL}$ of the upper organic layer was directly injected for analysis.

\section{Quality control}

The quality control (QC) samples were analyzed in each analytical run at concentrations of $25,100,400 \mathrm{ng} \cdot \mathrm{mL}^{-1}$. The relative standard deviation (RSD) of QC samples were all less than 15\%.

\section{Statistics}

The main pharmacokinetic parameters $\left(t_{1 / 2}, A U C_{0-t}, A U C_{0-\infty}\right)$ of paeonol were calculated by DAS 2.0.The $C_{\max }$ and $T_{\max }$ were as observed.

\section{Results}

\section{Specificity}

The chromatograms of blank plasma (A), $200 \mathrm{ng} \cdot \mathrm{mL}^{-1}$ paeonol standard (B), blank plasma spiked with $250 \mathrm{ng} \cdot \mathrm{mL}^{-1}$ paeonol standard (C), plasma sample 5 min after intragastric administration of purified paeonol (D), Moutan cortex decoction(E) and Rhubarbmoutan decoction $(\mathrm{F})$ were shown in Figure 3.

\section{Calibration and LOQ}

The calibration curve for plasma assay was constructed with the peak area of paeonol versus its concentration. The weighted regression equation $\left(1 / \mathrm{x}^{2}\right)$ of the calibration curve was $\mathrm{Y}=$ $-11652.36607+5207.71572 \mathrm{X}$ with a correlation coefficient $(\mathrm{r})$ of 0.9998 . The linear range was $10 \sim 500 \mathrm{ng} \cdot \mathrm{mL}^{-1}$ and the limit of quantity (LOQ) was $10 \mathrm{ng} \cdot \mathrm{mL}^{-1}$.

\section{Recovery, accuracy and precision}

The recovery, accuracy and precision of method were evaluated

\begin{tabular}{|c|c|c|c|c|c|}
\hline \multirow{2}{*}{$\begin{array}{l}\text { Nominal } \\
\text { concentration } \\
\left(\mathrm{ng} \cdot \mathrm{mL}^{-1}\right)\end{array}$} & \multicolumn{2}{|c|}{ Intra-day } & \multicolumn{2}{|l|}{ Inter-day } & \multirow{2}{*}{$\begin{array}{l}\text { Extraction } \\
\text { recovery (\%) }\end{array}$} \\
\hline & $\operatorname{RSD}(\%)$ & Accuracy $(\%)$ & $\operatorname{RSD}(\%)$ & $\begin{array}{l}\text { Accuracy } \\
(\%)\end{array}$ & \\
\hline 25 & 4.56 & $99.88 \pm 4.56$ & 13.72 & $95.60 \pm 13.04$ & $92.28 \pm 5.90$ \\
\hline 100 & 1.21 & $97.92 \pm 1.97$ & 3.59 & $97.91 \pm 1.70$ & $97.44 \pm 3.46$ \\
\hline 400 & 2.34 & $89.86 \pm 2.10$ & 3.77 & $88.30 \pm 3.33$ & $97.34 \pm 3.05$ \\
\hline
\end{tabular}

Table 1: Precision and recovery of paeonol $(n=5)$.

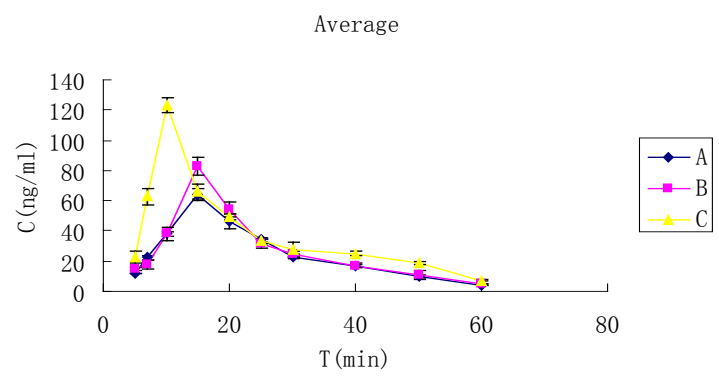

Figure 4: Mean plasma concentration-time curves after intragastric administration $\left(10 \mathrm{mg} \cdot \mathrm{kg}^{-1}\right)$ of purified paeonol (A), Moutan cortex decoction(B) and Rhubarbmoutan decoction(C).

\begin{tabular}{|l|l|l|l|}
\hline Parameters & Purified paeonol & $\begin{array}{l}\text { Moutan cortex } \\
\text { decoction }\end{array}$ & $\begin{array}{l}\text { Rhubarb moutan } \\
\text { decoction }\end{array}$ \\
\hline$T_{\max } / \mathrm{min}$ & 15 & 15 & 10 \\
\hline$t_{1 / 2} / \mathrm{min}$ & $13.15 \pm 2.48$ & $15.04 \pm 4.40$ & $21.83 \pm 6.21$ \\
\hline$C_{\max } / \mathrm{ng} \cdot \mathrm{mL}^{-1}$ & $69.41 \pm 4.50$ & $82.90 \pm 6.10$ & $123.32 \pm 5.55$ \\
\hline$A \cup C_{0-t} / \mathrm{ng} \cdot \mathrm{mL} \cdot \mathrm{min}^{-1}$ & $1243.42 \pm 109.75$ & $1412.74 \pm 97.72$ & $2162.20 \pm 105.10$ \\
\hline$A \cup C_{0-\infty} / \mathrm{ng} \cdot \mathrm{mL} \cdot \mathrm{min}^{-1}$ & $2192.46 \pm 472.18$ & $2659.57 \pm 1590.70$ & $3423.36 \pm 465.40$ \\
\hline
\end{tabular}

Table 2: Main pharmacokinetic parameters of Paeonol $(\bar{x} \pm s, \mathrm{n}=6)$.

and dates were shown in Table 1 . The recoveries were ranged from $92.28 \%$ to $97.44 \%$. The intra-day and inter-day precisions were ranged $3.59 \% \sim 13.72 \%$ and $1.21 \% \sim 4.56 \%$. These results suggested that the procedures described as above were satisfactory with respect to both accuracy and precision.

\section{Time-plasma concentration curves}

Mean plasma concentration-time curves after intragastric administration (10 mg. $\mathrm{kg}^{-1}$ ) of purified paeonol (A), Moutan cortex decoction(B) and Rhubarbmoutan decoction $(\mathrm{C})$ were as shown in Figure 4.

\section{Pharmacokinetic parameters}

Paeonol pharmacokinetics of the main pharmacokinetic parameters of paeonol were calculated by DAS 2.0 after administration of purified paeonol, Moutan cortex decoction and Rhubarbmoutan decoction in mice were as shown in Table 2.

\section{Discussion}

Paeonol is easy to evaporate during decorating, extracting or drying processes because of its lower melting point. In order to decrease the loss of paeonol as much as possible, reflux condenser was applied to prepare for Moutan cortex decoction and Rhubarbmoutan decoction. In our study, $0.2 \mathrm{~mL}$ acetonitrile was used for protein precipitation and 40 50 mg sodium chloride was added to improve the extraction and the organic phase was directly injected for analysis. The mobile phase, phosphoric acid (containing 1\% triethylamine)-acetonitrile $(40: 60, \mathrm{v} / \mathrm{v})$, was stable and suitable for the determination of paeonol. The paeonol was well separated from endogenous substances at above chromatographic conditions.

The linear range of the paeonol was $10 \sim 500 \mathrm{ng} \cdot \mathrm{mL}^{-1}$ and the determination limit was $10 \mathrm{ng} \cdot \mathrm{mL}^{-1}$.The extraction recoveries of paeonol determined in high, medium and low concentrations were more than $92.28 \%$. RSD of intra-day and inter-day analysis were $<13.72 \%$. The method established here is simple, sensitive, accurate and suitable to determine the low plasma levels of paeonol and applied to its pharmacokinetic studies in mice.

The feature of Traditional Chinese Medicine theory is to emphasize the human overall view, which can regulate the whole process. Modern Pharmacology studies have proved the efficacy of Traditional Chinese Medicine is not simply the sum of the single herbs or toxicity subtraction, it also includes the synergy restriction or modified and others in various drugs. In the boiling process, the interaction among Chinese herbs will bring about chemical changes or transform into new products.

The differences of paeonol pharmcokinetics were existed in purified paeonol, Moutan cortex decoction and Rhubarbmoutan decoction in mice. The paeonol elimination speed is decreased $\left(t_{1 / 2}\right.$ was longer), and the absorption amount is increased $\left(C_{\max }\right.$ and $A U C$ were larger), in Rhubarbmoutan decoction than those of purified 
Citation: Jing W, Rui Z, Gui-yan Y, Rui-chen G (2011) Pharmacokinetics of Purified Paeonol and Paeonol in Moutan Cortex Decoction and Rhubarbmoutan Decoction. Pharm Anal Acta 2:124. doi:10.4172/2153-2435.1000124

Page 4 of 4

paeonol while in Moutan cortex decoction were between purified paeonol and Rhubarbmoutan decoction. On the contrary, $T_{\max }$ of paeonol in Rhubarbmoutan decoction was much shorter than those of others, indicating that paeonol disposition in mice were affected by other components in Moutan cortex, a Chinese Medicinal Herb, and Rhubarbmoutan, a Chinese Traditional Prescriptions.

\section{References}

1. State Pharmacopeia Committee of China (2005) Pharmacopoeia of The People's Republic of China. Beijing:Chemical Industry Press.Part Two 119119 .

2. Xu LZ, He MY, Dai G (2005) J Clin Rehabil 9: 120-122.

3. Li F (2002) Pharmacology of Traditional Chinese Medicine Formulas. Beijing: People's Medical Publishing House 1: 299-307.

4. Chen XL, Lu Y, Du SY, Yao ZL, Wang S, et al. (2010) Determination of paeono in rat plasma by HPLC and pharmacokinetic study. Zhongguo Zhong Yao Za Zhi 35: 2826-2828.
5. Ma LY, Miu JH, Xu XD, Tang BL, Zhang Q (2009) J Lishizhen Medi and Mete Medi Res 20: 413-414.

6. Wu X, Chen H, Chen X, Hu Z (2003) Determination of paeonol in rat plasma by high-performance liquid chromatography and its application to pharmacokinetic studies following oral administration of Moutan cortex decoction. Biomed Chromatogr. 17: 504-508.

7. Zhi HY, Sun LF, Song JL, Li GS, Liu KJ (2009) Chin Trad and Herb Drug 40 731-734.

8. Wu J, Wang BJ, Wei CM, Kong XL, Guo RC (2007) J Clin Pharmacol Ther 12 935-937.

9. Wu X.J, Li G.X, Zhao LM (2007) J Chin Pharm 42: 863-865.

10. Zhang YX (2004) Pharmacology of Traditional Chinese Medicine New Theory. Beijing: People‘s Medical Publishing House 23-44.

11. Sun YC, Sun GP, Shen YX, Chen LM, Qu J, et al. (2006) J Chin Hosp Pharm 26: $543-545$ 